\title{
Epidemiological survey of zoonotic helminths in feral cats in Gran Canaria island (Macaronesian archipelago-Spain)
}

\author{
Eligia Rodríguez-Ponce ${ }^{1 *}$, Jorge F. González', Magnolia Conde de Felipe ${ }^{1}$, \\ Julia N. Hernández ${ }^{1}$ and J. Raduan Jaber ${ }^{2}$ \\ ${ }^{1}$ Department of Animal Pathology; ${ }^{2}$ Department of Morphology, Faculty of Veterinary, University of Las Palmas de Gran Canaria - \\ Trasmontaña s/n - 35413- Las Palmas
}

\begin{abstract}
The presence of zoonotic parasites in feral cats have been widely considered all over the world. In Gran Canaria (Macaronesian archipelago, Canary Islands, Spain) the number of feral cats has grown out of control in urban and rural areas. 48 of Felis catus captured in different Gran Canaria areas were studied. Animals were necropsied and several organs were systematically examined in order to collect and identify macroscopic parasites. In addition, coprological tests were done in 28 cats. There were no statistically significant differences in the prevalence rate among sex, age or capture area, showing an overall prevalence of helminths of $77.1 \%$. The most common tapeworms were Dipylidium caninum (64.6\%) and Taenia taeniaeformis (31.3\%), followed by the nematodes Toxocara cati (20.8\%), Ancylostoma tubaeforme (18.8\%), Aelurostrongylusabstrusus (10.4\%) and Trichuris vulpis (2.08\%). We also find several eggs of Alaria alata in the small intestine of one cat (2.08\%), being the first description of this trematode in cats in the Canary Islands. Aproximatelly, $40 \%$ of the studied cats harboured more than one parasite. High rates of zoonotic species found in these animals suggest the need of controling parasitic infections and preventive measures against them.
\end{abstract}

\section{Keywords}

Macaronesian archipelago, Canary Islands, prevalence, zoonosis, helminths, feral cat

\section{Introduction}

Although clinicians and researchers are aware about the role that feral and wildlife animals could have as potential reservoirs of many human diseases, the authorities and society are still not aware of this situation. Recent papers have highlighted that feral animals could potentially harbour many zoonotic parasites (Adams et al. 2008; Headley et al. 2012).

There are several surveys about the prevalence of parasites in feral animals from world-wide areas (Dubey et al. 2009; Stojanovic and Foley 2011). The increase of feral animals population close to the rural or urban areas may constitute the reservoir of many diseases that can be spread to human beings, as well as domestic animal species of our environment. (Beugnet et al. 2014).

Feral cats may become infected by several parasites, but helminths have shown the highest prevalence (Millán and Casanova 2009). Household cats may become infected by helminth cysts and eggs voided in the feces of feral cats and this may lead to human infection (Nichol et al. 1981a). Species such as Toxocara cati and Toxascaris leonina have an orofecal transmission cycle and produce infection by fecal contamination of food, water or the environment (gardens, sandpits and playgrounds) or direct contact (Overgaauw et al. 2009). Ancylostoma spp, has also been identified in cats (Millán and Casanova 2009; Coelho et al. 2011), representing another potential public health problem. Aelurostrongylus abstrusus has also been observed in feral cats from other countries such Spain and Portugal (Miró and Gómez 1999), producing respiratory problems. Recently, Dirofilaria immitis infection was diagnosed in household, as well as feral animals on the island of Gran Canaria (Morchón et al. 2004; MontoyaAlonso et al. 2011).

Gran Canaria is the second most densely populated island of Spain, as well as of Macaronesia, a collection of several archipelagos in the North Atlantic Ocean of the coast of Europe and Africa that belong to three countries: Portugal, Spain, and Cape Verde. Its geographical situation and the number of 
visitors (more than 2.2 million each year) are very important in terms of the potential for many of these parasites to be transmitted to humans, thus the zoonotic connection. In the countryside of Gran Canaria exists abundant population of feral cats that -as in other locations- do not receive any treatment against parasites, but they have access to food resources other than wild preys, such as farms or garbage bins; thus they usually being in good physical conditions and therefore these animals may survive with parasites (Millan and Casanova 2009). These factors and the difficulty in controlling the droppings of feral cats makes necessary to pay special attention to controlling parasites (ESCCAP 2010).

The study of the parasitological status of cats is important to establish the role of these animals as a potential hazard to human and animal health. Therefore, the aim of the present work was to determine the prevalence -by means of coproparasitological examinations and parasitological necropsyand evaluate the parasites in feral cats in different areas of Gran Canaria.

\section{Materials and Methods}

In this study, 48 feral cats (Felis catus) captured in Gran Canaria (Canary Islands, Spain) during authorized predator con- trol campaigns were studied. These animals were collected from different Gran Canaria locations following the scheme of climate zones described by Rodriguez-Ponce et al. (1995). Four different isoclimatic zones are found on Gran Canaria, ascending in altitude from the coast to the central peak of the island: Dry and Desert zone (DD), Dry and Steppe zone (DS), Temperate Mild zone (TM), and Temperate Cold zone (TC). All these areas were classified in two groups in relation to the climatic zone similarities; "coast area" (Dry zones: area number 1) and "central and top areas" (Temperate zones : area number 2) (Fig. 1).

Of the cats analyzed, 36 were adults (20 males, $16 \mathrm{fe}-$ males) and 12 juveniles ( $<12$ months, 4 males, 8 females). Animals were anesthetized with a combination of ketamine (Imalgene ${ }^{\circledR}$, Merial, France) and xylazine (Rompun ${ }^{\circledR}$, Bayer, Spain) and then humanely euthanized with intravenous injection of sodium pentobarbital (Dolethal ${ }^{\circledR}$, Vetoquinol). This protocol was done following the recommendations approved by the Ethical Committee of the Veterinary Faculty of Las Palmas de Gran Canaria University (Protocol 52/2009).

Each animal was necropsied to examine different organs such as the esophagus, trachea, lungs, heart, stomach, small and large intestines. Parasites obtained from these organs were stored in $70 \%$ ethanol. For Cestodes, the specimens were stained with carmine, differentiated in acid-alcohol, dehy-

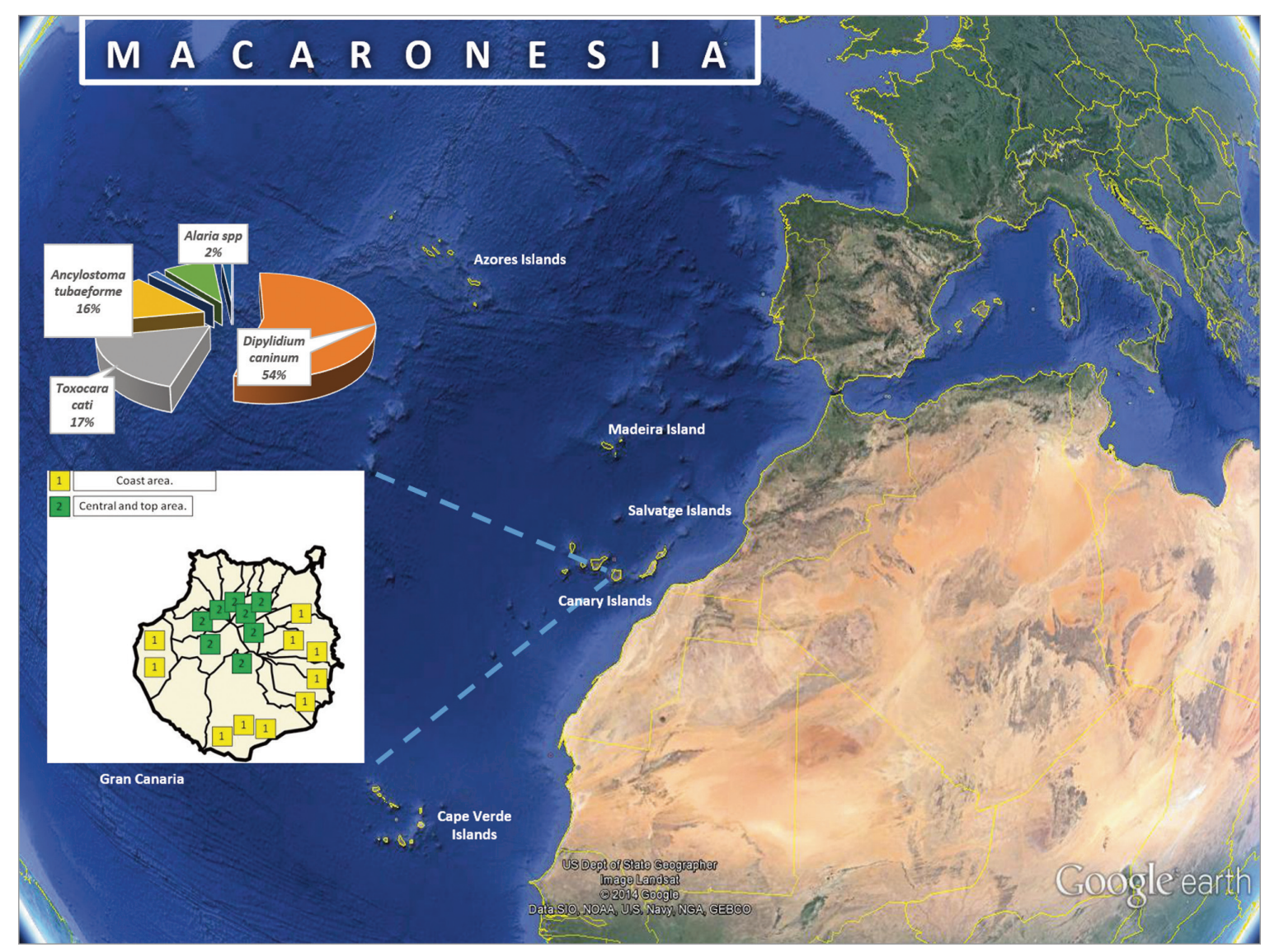

Fig. 1. Cartographical distribution of different regions where the feral cats were captured 


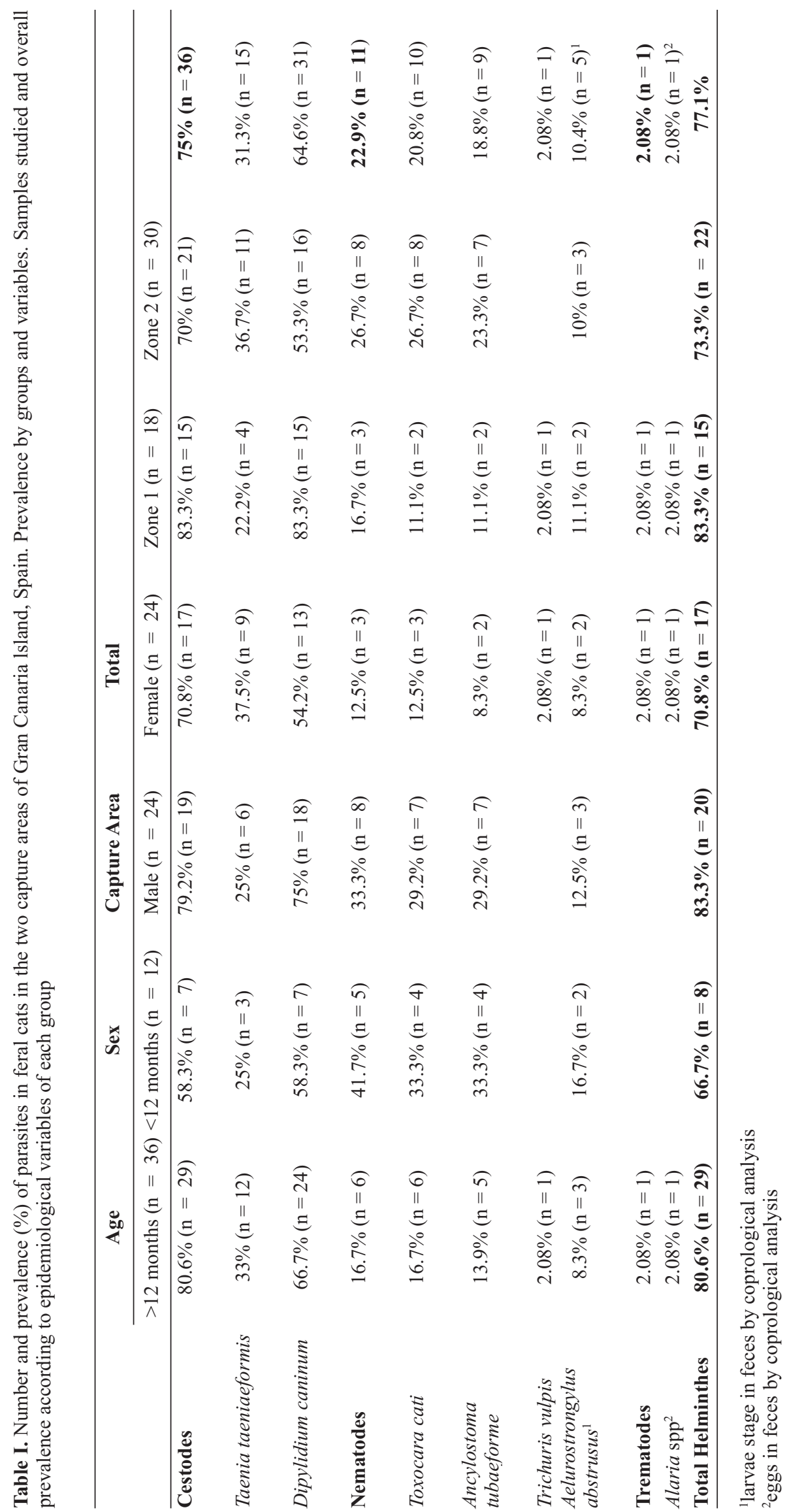




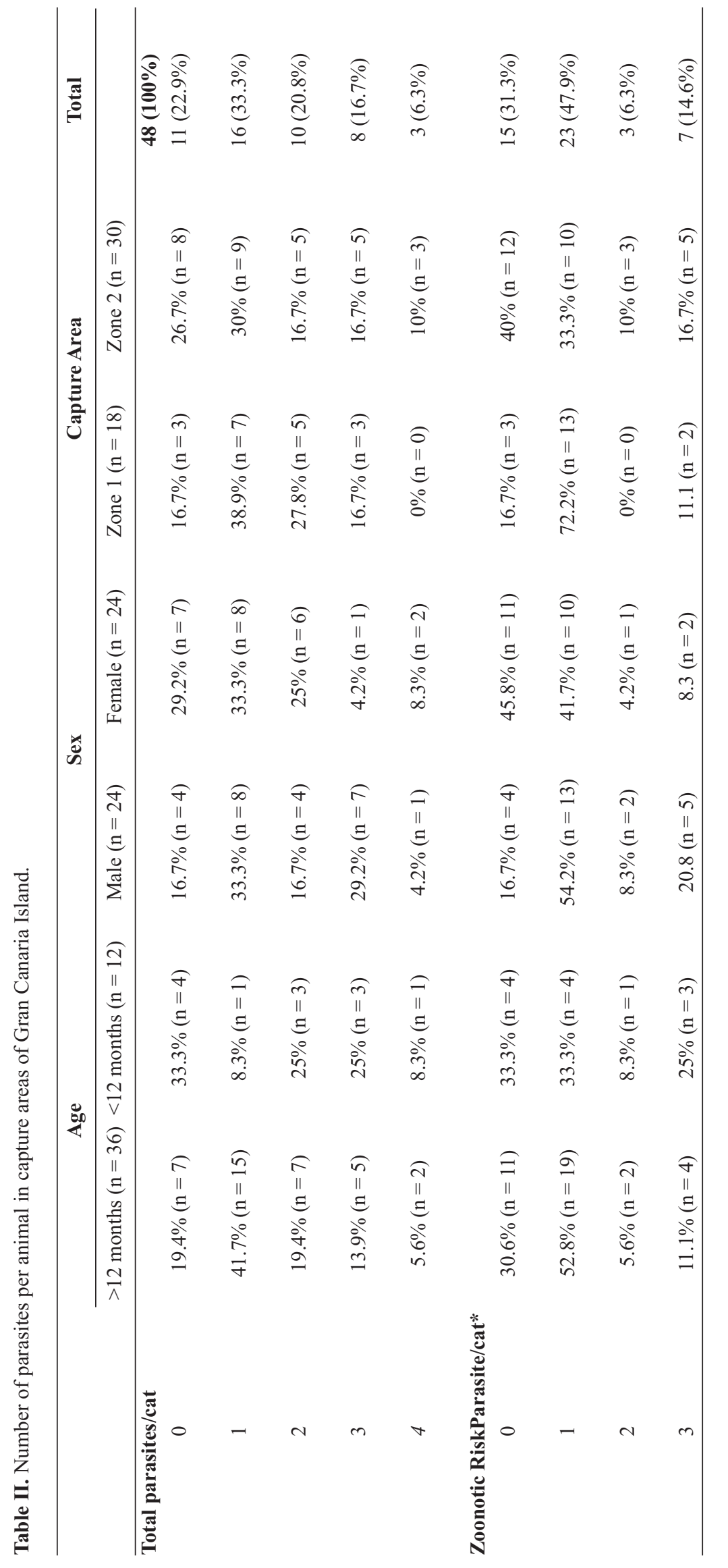


drated in serial concentrations of ethanol, cleared in xylene, mounted in DPX, and then identified morphologically to species according to existing descriptions and keys (Yamaguti 1958, 1959; Schmidt 1986). Nematode specimens were fixed in $70 \%(\mathrm{v} / \mathrm{v})$ warm ethanol and stored in $70 \%$ ethanol containing 5\% glycerol before being cleared by lactophenol and identified to species according to existing descriptions and keys (Skrjabin et al. 1991).

Faecal samples collected from the intestine were examined for parasitic infection. Ether-sedimentation and saturated sodium chloride flotation techniques were used to identify by light microscopy the parasitic dissemination elements.

Statistical analysis was done using SPSSâ (version 21.0). Chi-squared test $\left(\chi^{2}\right)$ was used to compare prevalence between age, sex or capture zone and parasite infection rates. Differences were considered significant at $p<0.05$. Confidence intervals $(95 \%)$ were calculated by means of exact ClopperPearson method.

\section{Results}

Most of the analyzed cats showed at least one species of helminth (77.1\%). Seven helminth species (one trematode, two cestodes and four nematodes) were identified base on their morphology (Table I).

Cestodes were the most prevalent (75\%) and 36 out of 48 cats were positive at least to one species of cestode, being Dipylidium caninum (64.6\%) and Taenia taeniformis (31.3\%) the only species observed. In the case of nematodes, the prevalence was $22.9 \%$ and there were four species detected: Toxocara cati (20.8\%), Ancylostoma tubaeforme (18.8\%), Aelurostrongylus abstrusus (10.4\%) and Trichuris vulpis (2.08\%) (Table I). Interestingly, Dirofilaria immitis was not detected in any of the animals of the present study.

High prevalence of zoonotic parasitic helminthes was found, and $68.7 \%$ of the cats were parasitized by at least one of the five potential zoonotic parasite found: 23 cats (47.9\%) harbored a single zoonotic species, 3 cats $(6.3 \%)$ harbored two zoonotic species and other 7 cats three zoonotic species. Only $22.9 \%$ were negative to any parasite (Table II).

The fecal samples done in 28 out of 48 animals showed the occurrence of single infections and co-infections by different species of parasites (58.3\%). Five of these animals revealed the presence of L1 of Aelurostrongylus spp. However, in relation to trematodes, only one animal showed Alaria spp. eggs.

There were not significative differences between sex, weight and age, and captured areas. No relationship of captured areas with parasite prevalence was detected $(\mathrm{p}=0.5)$.

\section{Discussion}

In touristic areas, close contact of cats with humans can increase transmission of zoonotic diseases and affect public health (Soriano et al. 2010). There are potential feline transmitted zoonotic parasites, such as Dypilidium caninum, Toxocara spp, Ancylostoma tubaeforme and Dirofilaria inmmitis that have been reported in different countries (Fenoy et al. 1997; Overgaauw 1997; Millán and Casanova 2009; Genchi et al. 2011). In the present study, the feral cats harbored five zoonotic parasites, Ancylostoma tubaeforme, Toxocara cati, Dipylidium caninum, Taenia taeniformis and Trichuris vulpis, showing a prevalence of $18.8 \%, 20.8 \%, 64.6 \%, 31.3 \%$ and $2.08 \%$ respectively. In Gran Canaria, as in many touristic areas, cats freely scavenge rubbish, gardens and street for food. In addition, tourists find that feeding these stray animals contribute to their welfare. This factor, couple with the public's poor understanding of disease transmission, and the hazards of pet faeces with respect to transmitting infectious diseases, underscores the importance of education in reducing the incidence of infections to avoid its transmission to other pets and humans.

Although numerous studies have described the worldwide prevalence of intestinal parasites in feral cats, only few published reports involved feline populations in the Canary Islands (Sánchez 2013). The overall prevalence of $77.1 \%$ of helminthes in this study was higher than that reported in other studies involving stray cats in Spain (Miró et al.. 2004; Torres et al. 2006), Portugal (23.1\%) (Duarte et al. 2010), Germany (33.6\%) (Becker et al. 2012) and the UK (34.8\%) (Nichol et al. 1981b). However, our data are in accordance with those reported by Millán and Casanova (2009) in Majorca Island (Spain) -another popular Spanish tourist destination in Europe- where all the 58 feral cats were parasitized by at least one specie of helminth. This high prevalence could suggest a lack of parasite control and easier access to intermediate hosts as have been reported in other studies (Calvete et al. 1998; Millán and Casanova 2009).

In relation to the detected species in this study, Dipylidium caninum (64.6\%), followed by Taenia taeniaeformis (31.3\%) showed the highest prevalence. The abundance of cestodes has been reported in the small intestine of dogs, cats, mice and wild carnivores since 1959 by Jimenez and continues to be valid nowadays (Calvete et al. 1998; Millán and Casanova 2007, 2009).

The ascarid, Toxocara cati (20.8\%) and the hookworm, Ancylostoma tubaeforme (18.8\%) were the most commonly detected nematode. Necropsy surveys have shown that these worms represent the most common intestinal helminth parasites of cats worldwide (Barutzki and Schaper 2003; Ferreira et al. 2011), both with zoonotic potential. The prevalence of Toxocara infections in our study was similar to that found in stray cats and animal shelters (Calvete et al. 1998; Robben et al. 2004; Gracenea et al. 2009; Millán and Casanova 2009). However, lower prevalence has been observed in faecal analysis in households cats (Overgaauw et al. 2009), which is probably related with a lower exposure rate and the preventive deworming treatments. In the case of Ancylostoma tubaeforme, the prevalence found in this study was $18.8 \%$. Other 
studies on feral cats elsewhere have found similar results (Coman et al. 1981; Shaw et al. 1983; Vanparijs et al. 1991). In contrast, higher prevalence (91\%) was observed in the gastrointestinal tract of cats analysed in Balearic Island, Spain (Millán and Casanova 2009). These two helminth species (Toxocara and Ancylostoma) may produce several larva migrans syndromes, including severe ocular or neurological damage in humans in case of Toxocara (Lee et al. 2010). Data obtained in this survey suggest that cats may constitute a potential source of infection to domestic animals and humans and can contribute significantly to the environmental burdens of these parasites in rural and urban areas. This fact has been recognized by several authors as being a significant feature in the spread of zoonotic and animal parasites (Széll et al. 2013).

Alaria spp. was found in this survey parasitizing the small intestine in one of the feral cats. This could be the first report of the presence of Alaria spp. in the Macaronesian area. However, we only detected the presence of Alaria spp. eggs in faeces, but not any parasite adults were observed in the intestine. This finding could suggest a pseudoparasitism originated by predation of some prey. Infestations by trematodes of genus Alaria are common in wild carnivores in many european countries (Criado-Fornelio et al. 2000; Wolfe et al. 2001; Segovia et al. 2003; Moks et al. 2006; Saeed et al. 2006). Infection are generally non-pathogenic for cats and dogs (Zajac and Conboy 2006). Although there are not been reported human cases of alariosis in Europe (Rentería-Solís et al. 2013), it is evident that a zoonotic risk can be presumed and a potential danger of this parasite has to be taken into consideration (Mohl et al. 2009; Portier et al. 2011). Therefore, the German Federal Institute for Risk Assessment (BfR), in its opinion No.027/2007, 1 July 2007 (Anonymous 2007), emphasized the pathogenic potential of this parasite.

Aelurostrongylus abstrusus was found in the faeces of five of the analysed animals (10.4\%). This is the first description of these lungworms in the Canary Islands (Spain). Bronchopulmonary infestations by A. abstrusus have been well documented in cats throughout most European countries with similar prevalence rates that ranged from $1 \%$ to $24.4 \%$, according to sampled populations and detection procedures (e.g., copromicroscopy or molecular detection) (Grandi et al. 2005; Taubert et al. 2009; Jefferies et al. 2010; Traversa et al. 2010). In the present study, lizards and birds were found in the digestive tract of our animals, suggesting that they could act as paratenic hosts for many metastrongylid species when they are predated upon by cats, as has been reported by Jefferies et al. (2010). Recent reports have indicated that infection in cats may be much more common than previously thought in endemic areas of Europe (Payo-Puente et al. 2008; Traversa et al. 2008, 2010). Moreover, emphasis should be placed on the diversity and potential for co-infections of cat metastrongylid species in Europe (Jefferies et al. 2010).

Interestingly, in spite of the high prevalence of Dirofilaria immitis in dogs from Gran Canaria, this parasite was not detected in any of the heart samples examined. Nevertheless, re- ports done by Montoya-Alonso et al. (2011) in cats from Gran Canaria island showed high seroprevalence (33\%) using a commercial ELISA test kit. This high percentage could be due to tests used for the detection of circulating antibodies may overestimate the number of infected cats, with a high number of false positives (Berdoulay et al. 2004).

In conclusion, the present study demonstrated that the prevalence of parasites in feral cats in Gran Canaria island was high. These animals are reservoir of helminthes that may affect their health status and increase the zoonotic risk. We did not found differences between age, sex and captured areas parameters, suggesting a widespread distribution of helminth infective forms. Rates of intestinal and lung parasites and of zoonotic species found in feral cats in this study suggest the need of controlling these parasitic infections through regular diagnostic testing, effective therapeutic protocols and preventive measures.

Acknowledgments. We wish to thank Dr. Oscar M. González-Díaz for their constructive comments and Rafael Riera from Gestión y Planeamiento Territorial y Medioambiental (GESPLAN) from the Canary Government that provided us all the animals of the study. This work was partially funded by GESPLAN, the Agencia Canaria de Investigación, Innovación y Sociedad de la Información (ACIISI) and the Programa de Ayudas de Formación del Personal Investigador of the Canary Government.

\section{Financial support}

This research received no specific grant from any funding agency, commercial or not-for-profit sectors.

\section{Conflict of interest}

The authors declare no conflict of interest

\section{References}

Adams P.J., Elliot A.D., Algar D., Brazell R.I. 2008. Gastrointestinal parasites of feral cats from Christmas Island. Australian Veterinary Journal, 86, 60-63. DOI: 10.1111/j.1751-0813.2007.00246.x

Anonymous. 2007. Bundesinstitut für Risikobewertung Wildschweinfleisch kann den gefa"hrlichen Dunckerschen Muskelegel enthalten. Stellungnahme Nr.027/2007 des BfR, 1 July 2007. Available at http://www.bfr.bund.de/cm/343/wildschweinfleisch kann den gesundheitsgefaehrlichen dunckerschen_muskelegel_enthalten.pdf (accessed 9 January 2013)

Barutzki D., Schaper R. 2003. Endoparasites in dogs and cats in Germany 1999-2002. Parasitology Research, Suppl 3, S148-150

Becker A.C., Rohen M., Epe C., Schnieder T. 2012. Prevalence of endoparasites in stray and forested dogs and cats in Northern Germany. Parasitology Research, 111, 849-857. DOI: 10.1007/s00436-012-2909-7

Berdoulay P., Levy J.K., Snyder P.S., Pegelow M.J., Hooks J.L., Tavares L.M., Gibson N.M., Salute M.E. 2004. Comparison of serological tests for the detection of natural heartworm infection in cats. Journal of American Animal Hospital Association, 40, 376-384

Beugnet F., Bourdeau P., Chalvet-Monfray K., Cozma V., Farkas R., Guillot J., Halos L., Joachim A., Losson B., Miró G., Otranto D., Renaud M., Rinaldi L. 2014. Parasites of domestic owned cats in Europe:co-infestations and risk factors. Parasites \& Vectors, 7, 291. DOI: 10.1186/1756-3305-7-291 
Calvete C., Lucientes J., Castillo J.A., Estrada R., Gracia M.J., Peribanez M.A., Ferrer M. 1998. Gastrointestinal helminth parasites in stray cats from the mid-Ebro Valley, Spain. Veterinary Parasitology, 75, 235-240

Coelho W.M., Amarante A.F., Apolinário J.C., Coelho N.M., Bresciani K.D. 2011. Occurrence of Ancylostoma in dogs, cats and public places from Andradina city, São Paulo state, Brazil. Revista do Instituto de Medicina Tropical de São Paulo, 53, 181184

Coman B.J., Jones E.H., Driesen M.A. 1981. Helminth parasites and arthropods of feral cats. Australian Veterinary Journal, 57, 324-327

Criado-Fornelio A., Gutierrez-Garcia L., Rodriguez-Caabeiro F., Reus-Garcia E., Roldan-Soriano M.A, Diaz-Sanchez M.A. 2000. A parasitological survey of wild red foxes (Vulpes vulpes) from the province of Guadalajara, Spain. Veterinary Parasitology, 92, 245-251

Duarte A., Castro I., Pereira da Fonseca I.M., Almeida V., Madeira de Carvalho L.M., Meireles J., Fazendeiro M.I., Tavares L., Vaz Y. 2010. Survey of infectious and parasitic diseases in stray cats at the Lis $\neg$ bon Metropolitan Area, Portugal. Journal of Feline Medicine and Surgery, 12, 441-446. DOI: 10.1016/ j.jfms.2009.11.003

Dubey J.P., Moura L., Majumdar D., Sundar N., Velmurugan G.V., Kwok O.C., Kelly P., Krecek R.C., Su C. 2009. Isolation and characterization of viable Toxoplasma gondii isolates revealed possible high frequency of mixed infection in feral cats ( Felis domesticus) from St Kitts, West Indies. Parasitology, 136, 589-594. DOI: 10.1017/S0031182009006015

ESCCAP (European Scientific Counsel Companion Animal Parasites). 2010. Guideline 01 second edition. Worm Control in dogs and cats

Fenoy S., Cuéllar C., Guillén J.L. 1997. Serological evidence of toxocariasis in patients from Spain with a clinical suspicion of visceral larva migrans. Journal of Helminthology, 71, 9-12

Ferreira F.S., Pereira-Baltasar P., Parreira R., Padre L., Vilhena M., Távora Tavira L., Atouguia J., Centeno-Lima S. 2011. Intestinal parasites in dogs and cats from the district of Évora, Portugal. Veterinary Parasitology, 179, 242-245. DOI: 10.1016/ j.vetpar.2011.02.003

Genchi C., Kramer L.H., Rivasi F. 2011. Dirofilarial infections in Europe. Vector Borne Zoonotic Diseases, 11, 1307-1317. DOI: 10.1089/vbz.2010.0247

Gracenea M., Soledad-Gómez M., Torres J. 2009. Prevalence of intestinal parasite in shelter dogs and cats in the metropolitan area of Barcelona (Spain). Acta Parasitologica, 54, 73-77. DOI: $10.2478 / \mathrm{s} 11686-009-0005-7$

Grandi G., Calvi L.E., Venco L., Paratici C., Genchi C., Memmi D., Kramer L.H. 2005. Aelurostrongylus abstrusus (cat lungworm) infection in five cats from Italy. Veterinary Parasitology, 134, 177-182

Headley S.A., Gillen M.A., Sanches A.W., Satti M.Z. 2012. Platynosomum fastosum-induced chronic intrahepatic cholangitis and Spirometra spp. infections in feral cats from Grand Cayman. Journal of Helminthology, 86, 209-214. DOI: 10.1017/ S0022149X11000265

Jefferies R., Globokar Vrhovecb M., Wallnerc N., Roman Catalanc D. 2010. Aelurostrongylus abstrusus and Triglostrongylus sp. (Nematoda: Metastrongyloidea) infections in cats inhabiting Ibiza, Spain. Veterinary Parasitology, 173, 344-348. DOI: 10.1016/j.vetpar.2010.06.032

Jiménez-Millán F. 1959. Contribución al estudio de los helmintos parásitos de los animales domésticos. Revista Ibérica de Parasitología, 19, 25-68

Lee A.C.Y., Schantz P.M., Kazacos K.R., Montgomery S.P., Bowman D.D. 2010. Epidemiology and zoonotic aspects of as- carid infections in dogs and cats. Trends of Parasitology, 26, 155-161. DOI: 10.1016/j.pt.2010.01.002

Millán J., Casanova J.C. 2007. Helminth parasites of the endangered Iberian lynx (Lynx pardinus) and sympatric carnivores. Journal of Helminthology, 81, 377-380

Millán J., Casanova J.C. 2009. High prevalence of helminth parasites in feral cats in Majorca Island (Spain). Parasitology Research, 106, 183-188. DOI: 10.1007/s00436-009-1647-y

Miró G., Gómez M. 1999. Parasitosis Res $\neg$ piratorias y Cardiopulmonares. In: Parasitologia Veterinária. Editores: Cordero del Campillo, M. e Rojo Vasquez, F.A McGraw-Hill, Interamericana, pp. 696-697.

Miró G., Montoya A., Jiménez S., Frisuelos C., Mateo M., Fuentes I. 2004. Prevalence of antibodies to Toxoplasma gondii and intestinal parasites in stray, farm and household cats in Spain. Veterinary Parasitology, 126, 249-255

Mohl K., Grosse K., Hamedy A., Wuste T., Kabelitz P., Lucker E. 2009. Biology of Alaria spp. and human exposition risk to Alaria mesocercariae - a review. Parasitology Research, 105, 1-15. DOI: 10.1007/s00436-009-1444-7

Moks E., Jogisalu I., Saarma U., Talvik H., Jarvis T., Valdmann H. 2006. Helminthologic survey of the wolf(Canis lupus) in Estonia, with an emphasis on Echinococcus granulosus. Journal of Wildlife Diseases, 42, 359-365

Montoya-Alonso J.A., Carretón E., Corbera J.A., Juste M.C., Mellado I.,Morchón R., Simón F. 2011. Current prevalence of Dirofilaria immitis in dogs, cats and humans from the island of Gran Canaria, Spain. Veterinary Parasitology, 176, 291294. DOI: 10.1016/j.vetpar.2011.01.011

Morchón R., Ferreira A.C., Martín-Pacho J.R., Montoya A., Mortarino M., Genchi G., Simón, F. 2004. Specific IgG antibody response against antigens of Dirofilaria immitis and its Wolbachia endosymbiont bacterium in cats with natural and experimental infections. Veterinary Parasitology, 125, 313-321. DOI:10.1016/j.vetpar.2004.08.003

Nichol S., Ball S.J., Snow K.R. 1981a. Prevalence of intestinal parasites in domestic cats from the London area. The Veterinary Record, 109, 252-253

Nichol S., Ball S.J., Snow K.R. 1981b. Prevalence of intestinal parasites in feral cats in some urban areas of England. Veterinary Parasitology, 9, 107-110

Overgaauw P.A.M. 1997. Prevalence of intestinal nematodes of dogs and cats in the Netherlands. Veterinary Quarterly, 19, 14-17

Overgaauw P.A.M., Van Zutphen L.V., Hoek D., Yaya F.O., Roelfsema J., Pinelli E., Knapen F.V., Kortbeek L.M. 2009. Zoonotic parasites in fecal samples and fur from dogs and cats in The Netherlands. Veterinary Parasitology, 163, 115-122. DOI: $10.1016 /$ j.vetpar.2009.03.044

Payo-Puente P., Botelho-Dinis M., Carvaja Urueña A.M., PayoPuente M., Gonzalo-Orden J.M., Rojo-Vazquez F.A. 2008. Prevalence study of the lungworm Aelurostrongylus abstrusus in stray cats of Portugal. Journal of Feline Medicine and Surgery, 10, 242-246. DOI: 10.1016/j.jfms.2007.12.002.

Portier J., Jouet D., Ferté H., Gibout O., Heckmann A., Boireau P., Vallée I. 2011. New data in France on the trematode Alaria alata (Goeze, 1792) obtained during Trichinella inspections. Parasite, 18, 271-275

Rentería-Solís Z.M., Hamedy A., Michler F.U., Michler B.A., Lücker E., Stier N., Wibbelt G., Riehn K. 2013. Alaria alata mesocercariae in raccoons (Procyon lotor) in Germany. Parasitology Research, 112, 3595--3600. DOI: 10.1007/s00436013-3547-4

Robben S.R.M., le Nobel W.E., Döpfer D., Hendrikx W.M.L., Boersema J.H., Fransen F., Eysker M.E. 2004. Infections with helminths and-or protozoa in cats in animal shelters in the Netherlands. Tijdschrift Voor Diergeneeskunde, 129, 2-6 
Rodriguez-Ponce, E., Molina, J.M., Hernández, S., 1995. Seroprevalence of goat toxoplasmosis on Grand Canary Islands. Preventive Veterinary Medicine. 24: 229-234

Saeed I., Maddox-Hyttel C., Monrad J., Kapel C.M. 2006. Helminths of red foxes (Vulpes vulpes) in Denmark. Veterinary Parasitology, 139, 168-179

Sánchez S. 2013. Contribución al conocimiento de la parasitofauna (Helmintos y Artrópodos) de mamíferos no lagomorfos de $\mathrm{Ca}-$ narias. PhD University of Barcelona, pp. 425

Schmidt G.D. (Ed.). 1986. Handbook of tapeworm identification. CRC Press, Boca Raton

Segovia J.M., Guerrero R., Torres J., Miquel J., Feliu C. 2003. Ecological analyses of the intestinal helminth communities of the wolf, Canis lupus, in Spain. Folia Parasitologica, 50, 231236

Shaw J., Dunsmore J., Jakob-Hoff R. 1983. Prevalence of some gastrointestinal parasites in cats in the Perth area. Australian Veterinary Journal, 60, 151-152

Skrjabin K.I., Shikhobalova N.P., Mozgovoi A.A. 1991. Suborder Ascaridata Skrjabin, 1915. In: Skrjabin K.I. (ed) Key to parasitic nematodes. Amerind, New Delhi, pp. 423-595

Soriano S.V., Pierangeli N.B., Roccia I., Bergagna H.F.J., Lazzarini L.E., Celescinco A., Saiz M.S., Kossman A., Contreras P.A., Arias C., Basualdo J.A. 2010. A wide diversity of zoonotic intestinal parasites infects urban and rural dogs in Neuque'n, Patagonia, Argentina. Veterinary Parasitology, 167,81-85. DOI: 10.1016/j.vetpar.2009.09.048

Stojanovic V.L., Foley P. 2011. Infectious disease prevalence in a feral cat population on Prince Edward Island, Canada. Canadian Veterinary Journal, 52, 979-982

Széll Z., Marucci G., Pozio E., Sréter T. 2013. Echinococcus multilocularis and Trichinella spiralis in golden jackals (Canis aureus) of Hungary. Veterinary Parasitology, 197, 393-396. DOI:10.1016/j.vetpar.2013.04.032

Received: June 10, 2015

Revised: December 23, 2015

Accepted for publication: January 19, 2016
Taubert A., Pantchev N., Globokar Vrhovec M., Bauer C., Hermosilla C. 2009. Lungworm infections (Angiostrongylus vasorum, Crenosoma vulpis, Aelurostrongylus abstrusus) in dogs and cats in Germany and Denmark in 2003-2007. Veterinary Parasitology, 159, 175-180

Torres, J., Miquel, J., Casanova, J.C., Ribas, A., Feliu, C., Morand, S. 2006. Endoparasite species richness of Iberian carnivores: influences of host density and range distribution. Biodiversity and Conservation, 15:4619-4632. DOI: 10.1007/s10531-0055824-8

Traversa D., Di Cesare A., Milillo P., Iorio R., Otranto D. 2008 Aelurostrongylus abstrusus in a feline colony from central Italy: clinical features, diagnostic procedures and molecular characterization. Parasitology Research, 103,1191-1196. DOI: $10.1007 / \mathrm{s} 00436-008-1115-0$

Traversa D., Di Cesare A., Conboy G. 2010. Canine and feline cardiopulmonary parasitic nematodes in Europe: emerging and underestimated. Parasites \& Vectors, 3, 62. DOI: 10.1186/1756-3305-3-62

Vanparijs O., Hermans L., Van der Flaes L. 1991. Helminth and protozoan parasites in dogs and cats in Belgium. Veterinary Parasitology, 38, 67-73

Wolfe A., Hogan S., Maguire D., Fitzpatrick C., Vaughan L., Wall D., Hayden T.J., Mulcahy G. 2001. Red foxes (Vulpes vulpes) in Ireland as hosts for parasites of potential zoonotic and veterinary significance. The Veterinary Record, 149, 759-763

Yamaguti S. 1958. Systema Helminthum, vol 1. The digenetic trematodes of vertebrates. Interscience, New York

Yamaguti S. 1959. Systema Helminthum, vol 2. The cestodes ofvertebrates. Interscience, New York

Zajac A.M., Conboy G.A. 2006. Veterinary Clinical Parasitology, 7th edition. Blackwell Publishing; Ames, Iowa, pp. 64 
Reproduced with permission of the copyright owner. Further reproduction prohibited without permission. 